\title{
ANÁlise de CONTRATOS dE CONCESSÃo PARA A PRESTAÇÃo de SERVIÇOS DE ÁGUA E ESGOTO NO BRASIL
}

\author{
ANALYSIS OF CONCESSION AGREEMENTS FOR PROVISION OF WATER AND \\ SEWAGE SERVICES IN BRAZIL
}

\section{ALCEU DE CASTRO GALVÃO JUNIOR}

Engenheiro Civil. Mestre em Hidráulica e Saneamento - EESC/USP. Doutorando da Faculdade de Saúde Pública - FSP/USP. Analista de Regulação da Agência Reguladora de Serviços Públicos do Estado do Ceará - ARCE

\section{Mario Augusto Parente Monteiro}

Economista. Mestre em Administração de Empresas. Especialista em Políticas Públicas e Gestão Governamental. Coordenador Econômico-tarifário da Agência Reguladora de Serviços Públicos Delegados do EstadoCeará - ARCE. Professor-Adjunto da Universidade de Fortaleza - UNIFOR

$$
\text { Recebido: 08/05/06 Aceito: 18/09/06 }
$$

\section{RESUMO}

O presente estudo apresenta uma análise comparativa de aspectos específicos dos instrumentos contratuais de concessão dos serviços de abastecimento de água e coleta e tratamento de esgoto em quatro municípios brasileiros, firmados em anos recentes, no contexto da superação do modelo legal instituído pelo Planasa a partir da década de 1970. Os contratos foram avaliados quanto ao pagamento de outorga, tarifas, metas de cobertura e investimentos, regulação, fiscalização e controle social, e direitos dos usuários. A análise realizada evidenciou a falta de uniformidade no tratamento de questōes relevantes nas concessôes, sugerindo que tal fato decorra da indefinição de um novo marco regulatório aplicável ao setor de saneamento.

PALAVRAS-CHAVE: Concessão, contrato, regulação, saneamento.

\section{INTRODUÇÃO}

O Plano Nacional de Saneamento (Planasa) foi criado no ano de 1971, em um contexto de centralização das decisōes políticas no plano federal e de limitação das liberdades individuais e coletivas.

No Planasa, a condição para a participação dos municípios no plano era o repasse do patrimônio e das instalações existentes dos serviços de água e esgoto às Companhias Estaduais de Saneamento Básico (CESBs) (Soares, Netto e Bernardes, 2003). Na época, $25 \%$ dos municípios existentes não aderiram ao novo sistema (Turolla, 2002). Dentro deste modelo institucional, o único papel dos municípios era o de delegar a gestão dos serviços às CESBs, por meio de contrato, para poderem ser incluídos no plano e terem acesso aos financiamentos do então Banco Nacional da Habitação (BNH) (Britto, 2001).

Conforme descrição de Nascimento, Galvão Junior e Mesquita (2003), a principal característica dos contratos era a omissão dos municípios quanto à regulação e à fiscalização da prestação dos serviços, além da não fixação metas de qualidade e de atendimento. Desta forma, os contratos de concessão privilegiavam as concessionárias negando aos municípios qualquer controle sobre a execução dos serviços, a exemplo da política tarifária e das decisões sobre investimentos (Britto, 2001).

Neste cenário, o modelo de gestão dos serviços acarretou duplo papel para as CESBs: o papel de regulador - no planejamento, coordenação e definição dos padrōes de serviços - e o papel de regulado - quando responsável pela ope- ração dos sistemas de abastecimento de água e de esgotamento sanitário (Soares, Netto e Bernardes, 2003).

A única forma de pressão externa exercida sobre as CESBs durante o Planasa foi desempenhada pelo $\mathrm{BNH}$ por meio de instrumentos de liberação e corte das verbas. De fato, o BNH exercia o papel de agente regulador dos serviços (Silva, 2002).

Todavia, a ausência de qualquer outro mecanismo de controle social limitava a imposição de regras ao sistema. Outros mecanismos, como as legislações ambiental e de defesa do consumidor, só começaram a ser implantados na fase final do Planasa, com resultados ainda pouco visíveis no setor de saneamento. Entretanto estruturas em vigor há mais tempo, como o sistema de vigilância sanitária, passaram desapercebidas pelas CESBs, 
em decorrência da inoperância dos órgãos responsáveis pela observância do cumprimento de sua legislação.

Por meio de amplo aporte de recursos para investimentos, o Planasa proporcionou significativo aumento no atendimento à população por abastecimento de água, contribuindo para a redução da taxa de mortalidade infantil e a ampliação da expectativa de vida da população brasileira (Rezende e Heller, 2002).

Em meados dos anos 80, o Planasa foi extinto. Esta extinção deixou um vácuo institucional ainda mais agravado pelo vencimento, a partir do final da década seguinte, da maioria dos contratos de concessão assinados entre os municípios e as CESBs por períodos de trinta anos. As CESBs prestam serviços de abastecimento de água em 3.921 municípios, cuja população representa $75 \%$ da população urbana, e em 880 municípios com serviços de esgotamento sanitário (Brasil, 2004a).

A extinção do Planasa não foi seguida, no entanto, pela definição de um marco regulatório para o setor de saneamento. Tal ausência vem agravando o quadro institucional e tem como conseqüências disputas em torno da titularidade entre Estados e Municípios (Galvão Junior et al, 2004). Segundo Montenegro (2002), as CESBs estão enfrentando dificuldades na renovação das concessões em função dos municípios, sobretudo os superavitários, não aceitarem contratos que não reconheçam suas prerrogativas de titular dos serviços e da baixa capacidade de realização de novos investimentos nas concessões.

Por sua vez, de acordo com o projeto de lei $\mathrm{n}^{\circ} 7361 / 2006$, sobre diretrizes nacionais para o saneamento básico, aprovado no Senado Federal e que tramita na Câmara dos Deputados, os contratos deverão prever entre outros, o sistema de cobrança e a composição de tarifas, a sistemática de reajustes e de revisões, e os mecanismos de controle social nas atividades de planejamento, regulação e fiscalização dos serviços (Câmara dos Deputados, 2006). Ainda neste aspecto, o contrato de concessão deve ser claro, transparente nos direitos e obrigaçóes das partes, condição esta imprescindível para estabilizar as relaçôes entre poder concedente e concessionária (Nascimento, Galvão Junior e Mesquita, 2003).

Nesta perspectiva, este estudo foi desenvolvido visando analisar comparativamente contratos de concessão entre
Companhias Estaduais de Saneamento Básico e municípios, assinados em um ambiente desprovido de marco regulatório nacional e apontar as diferentes soluções propostas para as várias questôes institucionais do setor.

\section{METODOLOGIA}

Para a presente investigação utilizou-se estudo documental dos contratos de concessão do Brasil assinados no período de 2001 a 2003.

Por se tratar de contratos de concessão - documentos públicos - dentre os disponíveis foram analisados os contratos cujos critérios foram definidos com base nos seguintes aspectos: 1 . os contratos devem apresentar soluções diversas para as várias questóes institucionais do setor; 2. a renovação contratual deve ter sido realizada com as mesmas companhias estaduais que operavam os sistemas; e 3. os municípios devem ser capitais de Estados.

De acordo com os critérios citados, foram analisados quatro contratos dos seguintes municípios: Belo Horizonte (MG), com operação a cargo da Companhia de Saneamento de Minas Gerais (Copasa); Curitiba (PR), a cargo da Companhia de Saneamento do Paraná (Sanepar); Fortaleza (CE), a cargo da Companhia de Água e Esgoto do Ceará (Cagece); e Natal (RN), a cargo da Companhia de Águas e Esgotos do Rio Grande do Norte (Caern).

Para a análise dos contratos, as questôes institucionais foram divididas em cinco categorias de análise: pagamento de outorga; tarifas; metas de cobertura e investimentos; regulação, fiscalização e controle social; e direitos dos usuários.

Em virtude de se tratar de um escopo mais complexo, a categoria "tarifas" centra sua análise em torno dos pontos mais importantes no âmbito dos contratos de concessão analisados, e para tanto é dividida em subcategorias de análise, a saber:

- Definição dos conceitos de reajuste e de revisão tarifária;

- Estabelecimento da periodicidade de aplicação dos reajustes e das revisões ordinárias das tarifas;

- Definição da metodologia de fixação, reajuste e revisão das tarifas aplicáveis ao serviço;

- Fixação de parâmetros básicos a serem observados na estrutura tarifária da concessionária.
Quanto à renovação da concessão de Belo Horizonte há uma observação, qual seja, ela foi realizada por meio de um convênio entre o município e a concessionária, mas, para efeito didático, neste artigo tal instrumento jurídico é tratado como contrato. Da mesma forma, considera-se que o titular dos serviços é o município. Todavia esta questão será ainda definida no âmbito da Política Nacional de Saneamento Básico e conforme decisão do Supremo Tribunal Federal.

\section{RESULTADOS E DISCUSSÃO}

$\mathrm{Na}$ Tabela 1 podem ser observadas as características gerais das concessões analisadas pelos contratos no presente estudo.

Do ponto de vista das características das concessões, existiam algumas similaridades técnicas, embora os sistemas apresentassem escalas operacionais diferentes.

Conforme se observa pelos dados da Tabela 1, ao se analisar os índices de tratamento de esgoto verifica-se baixa cobertura nos municípios estudados. Já em relação ao atendimento de água, apenas Fortaleza, apresenta deficiências. Ainda, apesar do índice de atendimento urbano de esgoto de Belo Horizonte ser de $90,8 \%$, somente $34,5 \%$ do esgoto coletado é tratado (Tabela 1 ).

De acordo com a metodologia proposta, relaciona-se a seguir as diferentes categorias que subsidiam a análise dos contratos de concessão.

\section{Pagamento de outorga}

A exemplo do modelo de privatização dos setores de energia e telefonia, o pagamento de outorga pela concessão tem sido implementado em diversos contratos de prestação de serviços de água e esgoto no Brasil, especificamente nos sistemas autosustentáveis. Se por um lado o pagamento de outorga remunera o titular dos serviços, por outro retira recursos de um setor deficitário e carente de investimentos. Segundo afirmam Camargo e Santos (2002), ao comentarem sobre a não onerosidade da concessão expressa no então projeto de lei no 4.147/2001, esta medida reduz o impacto da ampliação dos serviços de água e esgoto sobre as tarifas bem como inibe a ganância de governantes 
para fazer caixa por meio da venda do patrimônio público. Da mesma forma, Turolla (2002) considera este dispositivo importante para evitar que recursos potenciais do sistema de saneamento sejam direcionados para outras finalidades e para impedir a utilização das concessões como instrumentos de arrecadação contingencial.

Pela Tabela 2 observa-se a forma como foi tratado o pagamento de outorga nos diferentes contratos de concessão analisados.

Conforme se constata, todas as concessóes analisadas apresentaram pagamento pela outorga da concessão, a despeito de cada contrato ter um formato diferenciado.

As concessões de Curitiba e Fortaleza, por exemplo, tiveram repasses onerosos importantes num prazo médio de dois anos após a assinatura dos contratos, coincidindo com a gestão dos prefeitos concedentes.

Os repasses principais para a concessão de Curitiba não mostraram vinculação quanto à sua aplicação, entretanto, o contrato de Fortaleza vinculou os repasses à obrigatoriedade de aplicação em obras de saneamento ambiental. Apesar de estar previsto um repasse de até $R \$ 170.000 .000,00$ para o município de Belo Horizonte pela Copasa, em forma de um programa de recuperação ambiental e saneamento, este recurso somente será desembolsado a partir de janeiro de 2008.

Nos contratos de Fortaleza e Natal, foram previstos repasses escalonados em termos de percentual sobre o faturamento mensal da concessionária e de valor anual, respectivamente, cujas aplicações estão vinculadas à execução de obras e melhorias nos sistemas de abastecimento de água e esgotamento sanitário definidas pelos municípios e executadas pelas concessionárias. Já os repasses de recursos da concessão de Belo Horizonte são encaminhados diretamente para o município para aplicação de parte destes no Fundo Municipal de Saneamento.

Dos contratos analisados, somente o de Fortaleza implicou a transferência de parte do controle acionário da concessionária para o município.

O déficit de cobertura dos serviços dos sistemas estudados, especificamente em esgotamento sanitário, conforme demonstrado na Tabela 1, coloca em dúvida os ganhos sociais e ambientais efetivos do pagamento de outorga pela renovação de concessões. Alguns municípios transformaram a renovação das concessões em uma oportunidade para transferir recursos do saneamento para o orçamento fiscal, o que provavelmente repercutiu nas metas e compromissos de investimentos em água e esgoto dos contratos. Esta questão ficou evidente, visto que a maior parte dos repasses principais, de dois dos quatro contratos analisados, foi transferida na gestão do prefeito concedente.

Por outro lado, a vinculação de repasses escalonados à execução de obras e melhorias de água e esgoto permite que o concedente interfira na concessão mediante direcionamento de prioridades, dentro dos limites estabelecidos nos respectivos contratos.

Como condição vinculante à outorga, os contratos de concessão de Belo Horizonte, Fortaleza e Natal definiram a participação dos concedentes nos conselhos de administração de suas respectivas concessionárias. Belo

Tabela I - Características gerais dos municípios e dos contratos de concessão

\begin{tabular}{|c|c|c|c|c|c|c|c|c|}
\hline \multirow[t]{2}{*}{ Município } & \multirow{2}{*}{$\begin{array}{l}\text { Pop. } \\
\text { Urbana } \\
\text { (1) }\end{array}$} & \multirow[t]{2}{*}{$\begin{array}{l}\text { Assinatura } \\
\text { ccontrato }\end{array}$} & \multirow{2}{*}{$\begin{array}{c}\text { Período } \\
\text { concessão } \\
\text { (anos) }\end{array}$} & \multicolumn{2}{|c|}{$\begin{array}{c}\text { Quant. } \\
\text { eonomias ativas }\end{array}$} & \multirow{2}{*}{$\begin{array}{l}\text { Índice } \\
\text { trat. } \\
\text { esgoto } \\
(\mathrm{I} 16)^{(3)}\end{array}$} & \multicolumn{2}{|c|}{$\begin{array}{c}\text { Indice de atend. } \\
\text { urbano }^{(2)}\end{array}$} \\
\hline & & & & $\begin{array}{c}\text { Água } \\
(\mathrm{A03})^{(3)}\end{array}$ & $\begin{array}{l}\text { Esgoto } \\
(\mathrm{E} 03)^{(3)}\end{array}$ & & $\begin{array}{l}\text { Água } \\
(\mathrm{I} 23)^{(3)}\end{array}$ & $\begin{array}{l}\text { Esgoto } \\
(\mathrm{I} 24)^{(3)}\end{array}$ \\
\hline B. Horizonte & 2.238 .256 & 2002 & 30 & 823.230 & 756.654 & 34,5 & 99,9 & 90,8 \\
\hline Curitiba & 1.587 .315 & 2001 & 30 & 561.048 & 422.195 & 84,6 & 99,9 & 74,6 \\
\hline Fortaleza & 2.141 .402 & 2003 & 30 & 623.872 & 373.459 & $100,0^{(4)}$ & 75,1 & 42,2 \\
\hline Natal & 712.737 & 2002 & 25 & 197.101 & 64.085 & 47,6 & 96,7 & 31,6 \\
\hline
\end{tabular}

(1)IBGE, 2001. Censo 2000.

(2) Brasil, 2004b - Sistema Nacional de Informação em Saneamento (SNIS) 2003.

(3) A03 - Quantidade de Economias Ativas de Água - Economias;

E03 - Quantidade de Economias Ativas de Esgoto - Economias;

I16 - Indice de Tratamento de Esgotos-\%;

I23 - Índice de Atendimento Urbano de Água-\%;

I24 - Índice de Atendimento Urbano de Esgoto Referido aos Municípios Atendidos com Água-\%;

Fonte: Brasil, 2004b - SNIS 2003.

(4) O tratamento de esgotos é do tipo preliminar seguido de disposição oceânica.

Tabela 2 - Pagamento de outorga nos contratos de concessão

\begin{tabular}{|c|c|c|c|c|c|c|c|}
\hline \multirow[t]{2}{*}{ Município } & \multicolumn{2}{|c|}{ Repasse Principal } & \multicolumn{2}{|c|}{ Repasse Escalonado } & \multicolumn{2}{|c|}{ Ações } & \multirow{2}{*}{$\begin{array}{c}\text { Total } \\
\text { Estimado } \\
(\mathrm{R} \$ \times 1.000)\end{array}$} \\
\hline & $\begin{array}{l}\mathrm{R} \$ \mathrm{x} \\
1.000\end{array}$ & $\begin{array}{c}\% \text { pago até } \\
\text { dez/04 }\end{array}$ & Valor & Periodicidade & $\begin{array}{l}\mathrm{R} \$ \mathrm{x} \\
1.000\end{array}$ & $\begin{array}{c}\% \text { Capital } \\
\text { social }\end{array}$ & \\
\hline B. Horizonte & 170.000 & 0 & $4 \%$ arrec. tarifas & Mensal & - & - & - \\
\hline Curitiba & 125.000 & 43 & - & - & - & - & 125.000 \\
\hline Fortaleza & 15.000 & 100 & $1,5 \%$ faturamento & Mensal & 140.354 & 22 & 233.354 \\
\hline Natal & - & - & $\mathrm{R} \$ 1.000 .000$ & Anual & - & - & 25.000 \\
\hline
\end{tabular}

Fonte: Contratos de concessão dos municípios. 
Horizonte e Fortaleza também tiveram direito a participação no conselho fiscal da concessionária.

\section{Tarifas}

Um dos pressupostos básicos para a prestação dos serviços de abastecimento de água e esgotamento sanitário consiste no equilíbrio econômico-financeiro dos contratos de concessão. Por sua vez, a obtenção de tal equilíbrio passa pela definição de procedimentos de fixação e de alteração de tarifas que reflitam, de modo adequado, todos os reais custos associados à prestação dos serviços ora referidos. Segundo reportam Faria e Faria (2004), historicamente os prestadores de serviços não têm conseguido manter as tarifas em um nível adequado para cobrir os custos de operação e manutenção dos serviços.

Nesse sentido, os dispositivos contratuais relativos às questōes tarifárias, assumem grande relevância na medida em que contribuem para a estabilidade e transparência necessárias ao atendimento das demandas do poder concedente (eficiência), da empresa concessionária (equilíbrio econômicofinanceiro) e dos usuários (modicidade tarifária). Uma das causas de conflitos entre prefeituras e CESBs é o fato de as companhias não demonstrarem suas planilhas de custo para fixação das tarifas (Brasil, 2004a).

A partir da análise comparativa dos contratos, conforme mostra a Tabela 3, é possível concluir que ainda predomina uma abordagem superficial e pouco transparente nos aspectos relacionados com a fixação e a alteração das tarifas dos serviços. Exemplo de tal assertiva pode ser encontrado no fato de que, a despeito de estabelecida a realização de reajustes e revisōes tarifárias em todos os contratos analisados, somente no contrato de Fortaleza é explicitada a metodologia a ser utilizada. Tal ausência é crítica, pois oculta da sociedade os critérios de decisão e os procedimentos de cálculo utilizados no reajuste e na revisão das tarifas, restringindo as possibilidades de acompanhamento e controle social da concessão. A falta de políticas e definições claras quanto às tarifas pode resultar em desestímulo para os investidores privados e em fonte de desestruturação econômico-financeira das empresas públicas concessionárias (Acqua-plan, 1995).
No tocante às revisões tarifárias, há menção em todos os contratos analisados à manutenção do equilíbrio econômico-financeiro dos contratos (ou, em sua forma alternativa, à cobertura de todos os custos e despesas associadas à prestação dos serviços pelas tarifas cobradas). Conforme observado, na maioria dos contratos analisados (Belo Horizonte, Curitiba e Natal), não são explicitados os componentes de custo a serem cobertos com o objetivo de obter-se o referido equilíbrio econômico-financeiro da concessão. Itens essenciais para a definição do equilíbrio econômicofinanceiro, como, por exemplo, base de remuneração de ativos e custo de capital, não são tratados nos citados contratos. Isto torna vaga e imprecisa a condição necessária para a realização de revisóes tarifárias. Como exposto por Faria e Faria (2004), diante das diferentes formas de reajuste das CESBs no país, urge a criação de um mecanismo legalmente instituído que estabeleça regras de reajustes tarifários e garanta o equilíbrio econômico-financeiro dos serviços.

Em relação à estrutura tarifária, a exemplo do ocorrido nos contratos de Fortaleza, Curitiba e Natal, cabe às CESBs defini-la, com observância de alguns parâmetros gerais de progressividade, estabelecidos nos contratos de Curitiba e Natal. Destaca-se aqui a inexistência de dispositivos contratuais que explicitamente condicionem a estrutura tarifária à avaliação prévia do poder concedente.

\section{Metas de cobertura e de investimentos}

As metas de cobertura e de investimentos são um dos aspectos mais relevantes dentro de um contrato de concessão. Por meio da formalização destes compromissos, a concessionária pode planejar suas ações de médio e longo prazo, e os usuários e o poder concedente têm definidos prazos de melhorias e de ampliações dos serviços, além de dispor de um instrumento de cobrança. Da mesma forma, as metas têm repercussão direta nas tarifas cobradas aos usuários dos serviços, pois todos os investimentos executados no contrato serão remunerados ao longo da concessão. De acordo com Ogera e Philippi Jr (2005), os usuários dos serviços não se importam com o tipo de gestão, se privada ou pública, mas com a qualidade, quantidade e universalidade da água e com a coleta, localização e tratamento do esgoto, pela possibilidade de garantir a saúde ambiental e humana.

Em razão do extenso prazo de uma concessão dos serviços de água e esgoto, geralmente trinta anos, as metas devem ser explícitas em intervalos de tempo de no máximo cinco anos. Isto permite serem os investimentos distribuídos de maneira mais uniforme ao longo da concessão.

$\mathrm{Na}$ Tabela 4 constam as metas de cobertura e de investimentos definidas nas concessōes em estudo.

Ao se observar as metas de cobertura e de investimentos, conforme evidenciado, a concessão de Belo Horizonte não as apresenta de forma definida em contrato.

O único contrato a definir o compromisso de universalização da prestação dos serviços de esgotamento sanitário é o de Natal, com data para atendimento no ano de 2017. Os contratos de Curitiba e Fortaleza fixam em $90 \%$ e $70 \%$, respectivamente, os limites máximos de cobertura para o esgotamento sanitário. Segundo Abicalil (2002), a universalização dos serviços passa, necessariamente, pela prioridade das demandas originadas pelo atendimento à população de baixa renda $\mathrm{e}$ cobertura dos serviços de esgotamento sanitário.

Além dos investimentos nas áreas de abastecimento de água e esgotamento sanitário, o contrato de Fortaleza prevê investimentos em infra-estrutura de recursos hídricos, sob a responsabilidade do governo do Estado do Ceará, interveniente no contrato de concessão.

Outra particularidade identificada nos contratos analisados é a vinculação de investimentos a valores faturados com a prestação dos serviços na concessão de Natal: $10 \%$ do faturamento bruto por ano.

\section{Regulação, fiscalização e controle social}

A ausência de regulação cria uma situação na qual os operadores se autoregulam, não se sujeitando a nenhum tipo de sanção pelo não cumprimento das metas estabelecidas, o que propicia gestôes ineficientes e o comprometimento da qualidade dos serviços, com 


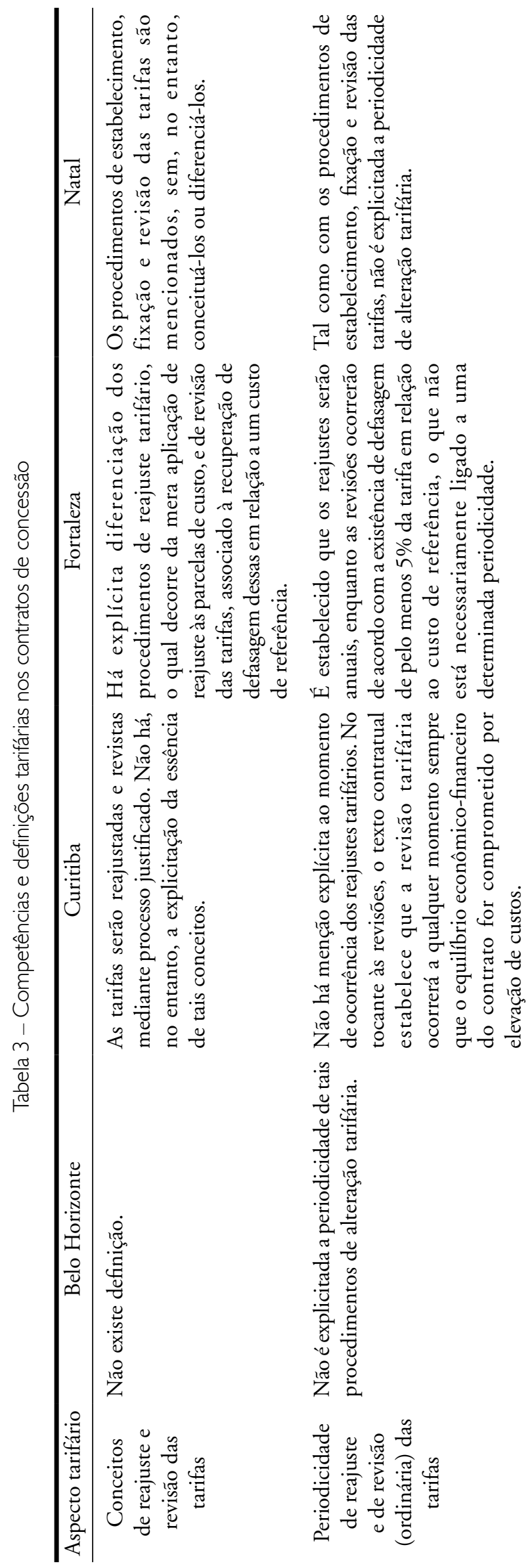

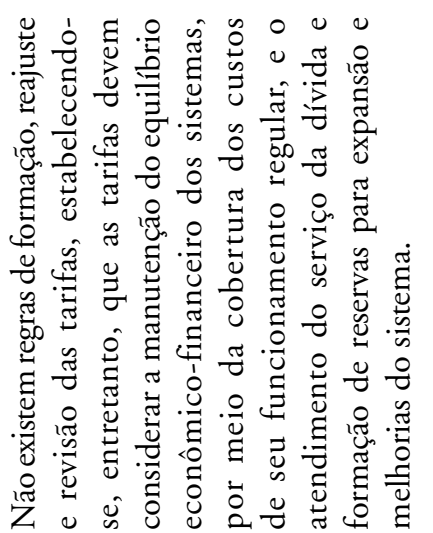

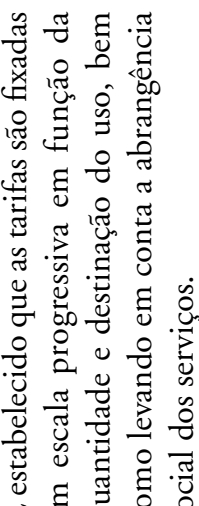

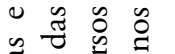

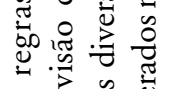

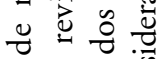

జ

艺

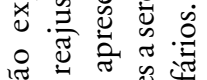

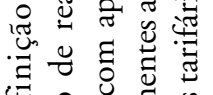

艺

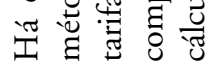

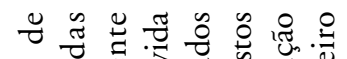

ఊ

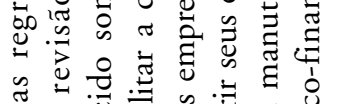

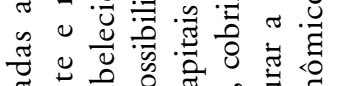

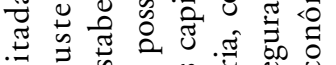

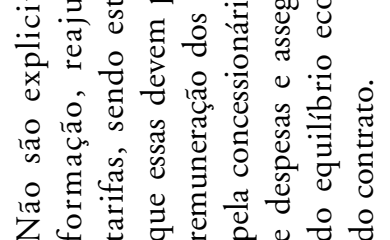

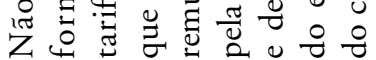

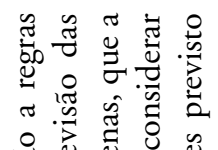

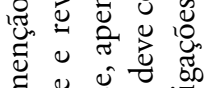

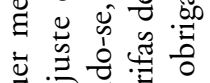

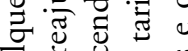

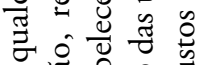

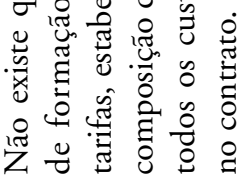

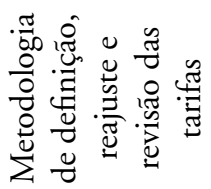

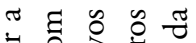

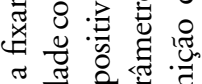

๙

สู

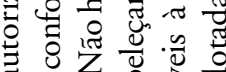

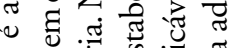

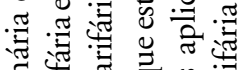

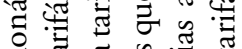

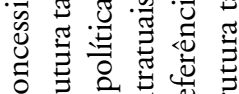

《

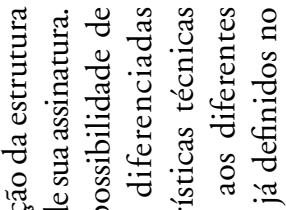

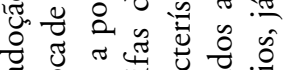

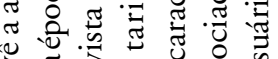

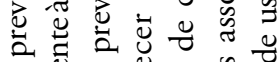

용

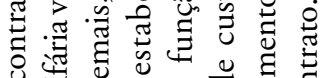

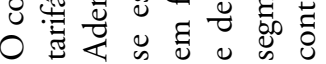
$-\pi$

$\overbrace{\pi}^{\pi}$

¿

㟧

ก)

讯通

离

赵

领

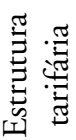


Tabela 4 - Metas de cobertura e de investimentos nos contratos de concessão

\begin{tabular}{|c|c|c|c|c|c|c|c|c|c|c|c|c|}
\hline \multirow[t]{2}{*}{ Concessão } & \multirow[t]{2}{*}{ Sistema } & \multicolumn{8}{|c|}{ Metas de Cobertura } & \multicolumn{3}{|c|}{$\begin{array}{l}\text { Metas de Investimentos } \\
(\mathrm{R} \$ \times 1.000)\end{array}$} \\
\hline & & Ano & $\%$ & Ano & $\%$ & Ano & $\%$ & Ano & $\%$ & Água & Esgoto & $\begin{array}{c}\text { Rec. } \\
\text { hídricos }\end{array}$ \\
\hline \multirow[t]{2}{*}{ Curitiba } & Água & 2004 & 100 & 2031 & 100 & - & - & - & - & - & - & - \\
\hline & Esgoto & 2004 & 82,1 & 2015 & 86,1 & 2020 & 90 & 2031 & 90 & & & \\
\hline \multirow[t]{2}{*}{ Fortaleza } & Água & 2003 & 90 & 2008 & 95 & 2023 & 100 & 2033 & 100 & 343.555 & 266.899 & 240.000 \\
\hline & Esgoto & 2003 & 48 & 2008 & 58 & 2023 & 70 & 2033 & 70 & & & \\
\hline \multirow[t]{2}{*}{ Natal } & Água & 2005 & 98 & 2007 & 100 & - & - & - & - & \multirow{2}{*}{\multicolumn{2}{|c|}{$\begin{array}{l}10 \% \text { Fat. bruto } \\
\text { por ano }\end{array}$}} & - \\
\hline & Esgoto & 2007 & 60 & 2009 & 80 & 2012 & 90 & 2017 & 100 & & & \\
\hline
\end{tabular}

Fonte: Contratos de concessão dos municípios

conseqüências danosas aos usuários e a toda a sociedade (Perosa, 2002).

No exercício pleno de suas prerrogativas, compete ao poder concedente o exercício da regulação e fiscalização da prestação dos serviços, podendo ter como tarefas intrínsecas a definição de tarifas, a outorga de reajustes e revisões tarifárias, a edição de resoluçōes e procedimentos para a prestação dos serviços, o acesso às instalações, obras e informaçóes da concessionária, entre outros. Turolla (2002) corrobora este entendimento ao afirmar que a política tarifária, o acompanhamento da execução de metas físicas do contrato e os demais aspectos da regulação econômica são de competência exclusiva do regulador designado pelo poder concedente.

As atividades de regulação e fiscalização dos serviços previstos nos contratos são executadas no âmbito dos municípios via órgãos da administração direta ou de entidades reguladoras. $\mathrm{Na}$ atividade reguladora exercida por órgão da administração direta, corre-se o risco de não se ter a independência necessária para a realização de regulação, e, desse modo, a concessão pode ser exposta a riscos de natureza política e conjuntural. Quando a regulação é efetuada por agências reguladoras, assegurada, pelo menos, autonomia financeira, por meio de taxa de regulação, e funcional, tem-se condiçôes efetivas para a estabilidade institucional e política da concessão. $\mathrm{Na}$ opinião de Conforto (1998), o ente regulador precisa preencher os requisitos técnicos necessários, ter autonomia quanto aos recursos de sua manutenção, que não podem estar condicionados ao orçamento geral do
Estado. Ainda segundo Britto (2001), um serviço essencial sob regime de monopólio como o saneamento básico exige uma regulação bem estruturada a fim de garantir sua universalização e evitar serem os cidadãos privados do acesso ou pagarem taxas excessivas pelos serviços prestados.

Outra forma de regulação e fiscalização ocorre mediante participação direta e indireta da sociedade e dos usuários dos serviços no controle da concessão. Esta participação, denominada de controle social, se dá de diversas formas, tais como análise de regulamentos, de regras de formação, reajuste e revisão das tarifas e de metas de expansão. De maneira geral, o controle social é operacionalizado por conselhos municipais ou de usuários, sejam de caráter consultivo ou deliberativo. Como afirma Turolla (2002), sob o ponto de vista da defesa do consumidor, a participação dos mesmos nas instâncias decisórias é fundamental.

A seguir são explicitados os contratos de concessão dos municípios objeto de estudo.

\section{Belo Horizonte}

O contrato de concessão de Belo Horizonte apenas explicita que o município deverá acompanhar e fiscalizar de forma permanente a prestação dos serviços por intermédio da Superintendência de Desenvolvimento da Capital (Sudecap).

No referido contrato não estão previstas as intervençôes do município quanto à regulamentação da prestação dos serviços e homologação de reajustes e revisōes tarifárias. Esta última, inclusive, de responsabilidade da Companhia Estadual. Ainda pelo contrato, a concessionária tem a obrigação de fornecer as informações necessárias ao acompanhamento da prestação dos serviços.

\section{Curitiba}

O contrato de Curitiba não trata do termo regulação em seu texto, ficando as atividades do concedente restritas à fiscalização da prestação dos serviços por meio de secretarias da administração direta do município.

No caso do acesso às instalações, obras e equipamentos, este é permitido ao concedente, desde que motivadamente requisitado à concessionária. Tal critério é adotado, também, para as informações e dados relativos à concessão.

Com relação à análise de reajuste e revisão de tarifas, o concedente não tem qualquer participação neste processo, e a responsabilidade é decorrente de proposta justificada da concessionária, homologada pelo Governador do Estado.

Quanto à normatização dos serviços, este papel cabe exclusivamente à concessionária.

\section{Fortaleza}

Compete ao município a fiscalização permanente da prestação dos serviços, a qual poderá ser delegada a uma agência reguladora municipal especificamente criada para este fim.

Entre as atribuiçōes do concedente encontra-se o acompanhamento das açóes da concessionária nas áreas contábil, comercial, técnica, econômica e financeira.

A fiscalização tem acesso às instalações e obras referentes à prestação dos serviços e pode requisitar à diretoria da concessionária as informações e dados necessários para o acompanhamento do contrato.

A proposta de reajuste (ou revisão) será apresentada ao município 
de Fortaleza (concedente) e ao Estado do Ceará (interveniente), a fim de que esses se manifestem a respeito, no prazo máximo de trinta dias, acerca da adequação dos procedimentos adotados na elaboração da proposta.

Embora o concedente disponha de poder normativo para assegurar a manutenção do serviço adequado, os regulamentos e normas da prestação dos serviços são de exclusividade da concessionária.

Não existe previsão direta de recursos para a agência reguladora. Entretanto a fórmula para reajuste das tarifas prevê a incorporação dos custos da taxa de regulação dos serviços.

\section{Natal}

Compete ao concedente o exercício da regulação e do controle efetivo da prestação dos serviços, indicando à concessionária as deficiências administrativas e operacionais, e apontando providências para a correção das irregularidades constatadas pelo órgão regulador.

A expedição de normas sobre a administração, expansão, operação, manutenção e comercialização dos serviços é de competência da concessionária, desde que ouvido o órgão regulador.

No estabelecimento, fixação e revisão de tarifas, haverá a participação do órgão regulador, mas a aprovação final destas é de competência do Conselho Municipal de Saneamento Básico.

Para o custeio das atividades de regulação, está previsto repasse mensal ao órgão regulador de $2 \%$ sobre o faturamento efetivamente arrecadado no âmbito do município de Natal nos primeiros cinco anos da concessão. A cada qüinqüênio, o percentual repassado ao órgão regulador é reduzido de 0,5\% até o limite de $1 \%$.

Ao Conselho Municipal de Saneamento Básico de Natal, responsável pelo controle social da concessão, compete a aprovação de reajustes e revisões tarifárias, a análise de planos diretores de água e esgoto do município, como das metas estabelecidas no contrato, entre outros. O conselho é um órgão colegiado composto por representantes dos poderes executivo e legislativo, empresa operadora, usuários, empregados da concessionária, instituições de ensino e pesquisa nas áreas de saneamento e de meio ambiente.

$\mathrm{Na}$ Tabela 5 estão resumidas as principais competências do poder

Tabela 5 - Competências reguladoras nos contratos de concessão

\begin{tabular}{|c|c|c|c|c|}
\hline \multirow[t]{2}{*}{ Competências } & \multicolumn{4}{|c|}{ Concessões } \\
\hline & Belo Horizonte & Curitiba & Fortaleza & Natal \\
\hline Normatizar & & & $\mathrm{X}$ & $\mathrm{X}$ \\
\hline $\begin{array}{l}\text { Homologar reajustes e } \\
\text { revisões tarifárias }\end{array}$ & & & $\mathrm{X}$ & $\mathrm{X}$ \\
\hline $\begin{array}{c}\text { Possibilitar acesso às } \\
\text { instalaçôes, obras e } \\
\text { equipamentos }\end{array}$ & & $\mathrm{X}$ & $\mathrm{X}$ & $\mathrm{X}$ \\
\hline $\begin{array}{l}\text { Possibilita acesso às } \\
\text { informaçóes e dados }\end{array}$ & $\mathrm{X}$ & $\mathrm{X}$ & $\mathrm{X}$ & $\mathrm{X}$ \\
\hline Receber taxa de regulação & & & $\mathrm{X}$ & $\mathrm{X}$ \\
\hline
\end{tabular}

Fonte: Contratos de concessão dos municípios

concedente identificadas nos contratos de concessão em análise.

De forma geral, segundo se observou cada contrato adotou um modelo regulatório diferente, com maior ou menor grau de intervenção do concedente na regulação dos serviços. Por exemplo, o modelo de regulação por agências, previsto em dois contratos - Natal e Fortaleza - admitiu concepçôes distintas de controle social por conselho municipal ou agência reguladora, respectivamente.

Em dois contratos - Natal e Fortaleza - está prevista a sustentabilidade financeira da atividade regulatória, um de forma direta e outro indireta, respectivamente. Desse modo, corre-se o risco de que, caso haja regulação - Belo Horizonte e Curitiba - nos demais contratos, a atividade venha a ser custeada por meio de orçamento fiscal. Isto, em tese, comprometeria a independência e a autonomia do agente regulador.

\section{Direitos dos usuários}

A melhoria do desempenho operacional das companhias de saneamento depende da conscientização dos clientes, pois, como consumidores que pagam suas contas, têm o direito de receber serviços de abastecimento de água e esgotamento sanitário adequados (Margulis et al, 2002). Como afirma Lazzarini (2002), os consumidores têm direito de acesso aos serviços de água e esgoto, à água segura, à informação, a ser ouvidos e participar, a reclamar e ter reparação, à educação para o consumo e a um ambiente saudável.

Os serviços públicos de abastecimento de água e de esgotamento sani- tário são de natureza essencial, devem ser prestados de forma adequada aos seus usuários com níveis satisfatórios de regularidade, continuidade, eficiência, segurança, atualidade, generalidade, cortesia e modicidade nas tarifas. Por serem estas condiçōes da prestação dos serviços bastante genéricas, é importante especificá-las devidamente nos contratos de concessão, bem como detalhá-las nos regulamentos da prestação dos serviços.

Dia-a-dia a exigência dos usuários e da sociedade pela melhoria da qualidade dos serviços vem aumentando progressivamente, com reflexos diretos nas demandas das legislaçóes ambiental, de saúde pública e de defesa do consumidor. Diante disto, urge a melhoria permanente da qualidade da prestação dos serviços para atendimento dos padrôes exigidos.

\section{$\underline{\text { Belo Horizonte }}$}

No contrato de concessão de Belo Horizonte não está prevista nenhuma cláusula específica acerca de direitos dos usuários dos serviços.

Conforme o texto do contrato, a concessionária deve prestar os serviços aos usuários de acordo com as normas contidas na legislação estadual específica. Nas atribuições comuns entre concessionária e concedente, está prevista a articulação de ações de interesse comum, no intuito de aperfeiçoar a qualidade do atendimento aos usuários dos serviços.

\section{Curitiba}

Entre as atribuições do poder concedente incluem-se o recebimento e o encaminhamento das reclamações dos usuários à concessionária, para que esta solucione as questôes. Da mesma forma, ao Estado do Paraná, interve- 
niente no contrato, compete obrigação semelhante.

No capítulo referente aos usuários, são listados direitos e obrigações genéricas já expressos em outras legislaçóes como o Código de Defesa do Consumidor, além da obrigatoriedade do cumprimento do regulamento da concessionária editado por decreto estadual.

\section{Fortaleza}

Os direitos dos usuários são elencados no contrato de forma genérica, tais como o recebimento dos serviços dentro das condiçóes estabelecidas nas normas e a disponibilização de informações para a defesa dos interesses individuais ou coletivos.

\section{$\underline{\text { Natal }}$}

Segundo o contrato de concessão, os usuários de Natal têm direito a receber serviços adequados, observados os princípios de generalidade e equidade em sua prestação. E ainda, como garantido o Código Sanitário do Município, receber do poder concedente, da concessionária e do órgão regulador as informações para a defesa de interesses individuais, coletivos ou difusos, bem como respostas às suas reclamações e, ainda, ter prévio conhecimento das paralisações, interrupções ou suspensões dos serviços.

Em caráter permanente, a concessionária deverá manter um órgão de atendimento aos usuários, com a finalidade específica de receber reclamações e sugestôes referentes à prestação dos serviços concedidos e seu aperfeiçoamento.

\section{CONCLUSÃO}

A análise comparativa de concessões renovadas em um ambiente institucional frágil e sem marco regulatório demonstrou, de forma geral, que cada contrato adotou soluçóes diferenciadas para questôes importantes como regulação, outorga, tarifas, entre outras.

Conforme observado, as indefinições legais no setor de saneamento, especialmente aquelas relacionadas à titularidade $\mathrm{e}$ às condiçōes para $\mathrm{a}$ prestação dos serviços, contribuem para a existência de lacunas contratuais comprometedoras da transparência e da eficiência requeridas pela sociedade, tanto do poder concedente, quanto da empresa concessionária.

As indefinições aqui mencionadas permitiram a negociação, no âmbito de cada contrato de concessão, de interes- ses específicos do poder concedente e das CESBs. Ademais, aliado à falta de um marco legal, o despreparo de concessionárias e concedentes, habituados ao dirigismo característico dos tempos do Planasa, implicou a inclusão de cláusulas inadequadas, ora para as concessionárias, ora para os concedentes.

Como solução para as questões apresentadas, urge a definição de um marco regulatório para o setor que aponte diretrizes gerais para concessão, regulação, tarifas, direitos e deveres, entre outros, e que também respeite o papel dos titulares em regulamentar os serviços sob sua concessão.

Finalmente, conclui-se que, na ausência do referido marco legal, os contratos a serem firmados devem observar a inclusão de cláusulas relativas aos seguintes aspectos: (i) metas de expansão da prestação dos serviços e dos investimentos requeridos; (ii) regras tarifárias transparentes e consistentes; (iii) formas de controle e regulação do setor pelo poder concedente; e (iv) definição precisa dos direitos e deveres do poder concedente e da empresa concessionária.

Cumpridas essas exigências, espera-se melhorar a qualidade dos contratos de concessão para a prestação de serviços de água e esgoto no Brasil.

\section{REFERÊNCIAS}

ABICALIL, M.T. Uma nova agenda para o saneamento. In: O PENSAMENTO DO SETOR SANEAMENTO NO BRASIL: PERSPECTIVAS FUTURAS. Brasília: PMSS, p.115-35, 2002.

ACQUA-PLAN - ESTUDOS, PROJETOS E CONSULTORIA. Flexibilização institucional da prestação de serviços de saneamento. Brasília: $\mathrm{Mi}-$ nistério do Planejamento e Orçamento. Secretaria de Política Urbana/IPEA, (Série Modernização do Setor de Saneamento, 3), 1995.

BELO HORIZONTE, Convênio de cooperação para a prestação compartilhada de serviços de abastecimento de água e saneamento básico. Belo Horizonte, Minas Gerais, 2002.

BRASIL, Cadernos MCidades Saneamento Ambiental - Saneamento ambienta v. 5 , 101p., 2004a.

BRASIL. Ministério das Cidades. Secretaria Nacional de Saneamento Ambiental. Programa de Modernização do Setor de Saneamento. Diagnóstico dos serviços de água e esgoto - 2003. Brasília, DF, 2004b.

BRITTO, A.L.N.P. A Regulação dos serviços de saneamento no Brasil: perspectiva histórica, contexto atual e novas exigências de uma regulação pública. In: IX ENCONTRO NACIONAL DA ANPUR, 3, 2001, Rio de Janeiro. Anais ... Rio de Janeiro, ANPUR, p.1080-93, 2001.
CÂMARA DOS DEPUTADOS. Projeto de Lei $\mathrm{n}^{\circ}$ 7.361. Estabelece diretrizes nacionais para o saneamento básico e dá outras providências. Disponível em: < http://www2.camara.gov.br/ proposicoes $>$. Acesso em: 31 ago. 2006.

CAMARGO, A., SANTOS, M.R.M. Universalização do saneamento: por uma gestão eficiente dos recursos escassos. In: O pensamento do setor saneamento no Brasil: perspectivas futuras. Brasília: PMSS, p.63-70, 2002.

CONFORTO, G. Descentralização e regulação da gestão de serviços públicos. Revista de Administração Pública, Rio de Janeiro, v. 32, n. 1, p. 27-40, Jan./Fev. 1998.

CURITIBA, Contrato de concessão para exploração de serviços públicos de abastecimento de água e de coleta, remoção e tratamento de esgotos sanitários. Curitiba, Paraná, 2001.

FARIA, S.A., FARIA, R.C. Cenários e perspectivas para o setor de saneamento e suas interfaces com os recursos hidricos. Engenharia Sanitária e Ambiental, v.9, n.3, p.202-10, Jul./Set. 2004.

FORTALEZA, Contrato de concessāo para exploração de serviços públicos de abastecimento de água e de coleta, remoção e tratamento de esgotos sanitários. Fortaleza, Ceará, 2003.

GALVÃO JUNIOR, A.C. et al. Fiscalização da qualidade dos serviços de água e esgoto no Brasil - um estudo de caso. In: XXIX CONGRESSO INTERAMERICANO DE INGENIERIA SANITARIA Y AMBIENTAL, San Juan de Puerto Rico. Anais...San Juan de Puerto Rico: AIDIS, CD-ROM, 2004.

IBGE - Instituto Brasileiro de Geografia e Estatística. Censo Demográfico 2000. Rio de Janeiro, 2001.

LAZZARINI, M. O saneamento e os consumidores. In: $\mathrm{O}$ pensamento do setor saneamento no Brasil: perspectivas futuras. Brasília: PMSS, p.79-84. 2002.

MARGULIS, S. et al. Brasil: a gestão da qualidade da água. Brasília: Banco Mundial, 72 p. 2002.

MONTENEGRO, M. H., apud REZENDE, S.C. e HELLER L. O saneamento no Brasil: politicas e interfaces. Belo Horizonte: Editora UFMG, 310 p. 202.

NASCIMENTO, G. L., GALVÃO JR, A.C., MESQUITA, A.M. Contrato padrāo para renovação das concessöes de água e esgoto. In: III CONGRESSO BRASILEIRO DE REGULAÇÃO DE SERVIÇOS PÚBLICOS CONCEDIDOS, Gramado. Anais...Gramado: ABAR, CD-ROM, 2003.

NATAL. Contrato de concessãa da prestação de serviços públicos de abastecimento de água e esgotamento sanitário. Natal, Rio Grande do Norte, 2002.

OGERA, R.C., PHILIPPI JR, A. Gestão dos serviços de água e esgoto nos municípios de Campinas, Santo André, São José dos Campos e Santos, no período de 1996 a 2000. Engenharia Sanitária e Ambiental, v.10, n.1, p.72-81, Jan./Mar. 2005.

PEROSA, P.T.Y. Regulação dos serviços de saneamento básico - aspectos conceituais e fatores intervenientes. São Paulo. [Dissertação de Mestrado FSP/USP], 2002. 
REZENDE, S.C., HELLER, L. O saneamento no Brasil: politicas e interfaces. Belo Horizonte: Editora UFMG, 310 p. 2002.

SILVA, R. T. Ordenamento institucional, tecnologia e perspectivas de integração dos serviços. In: $\mathrm{O}$ pensamento do setor saneamento no Brasil: perspectivas futuras. Brasília: PMSS, p.101-13, 2002.

SOARES, S.R.A., NETTO, O.M.C. e BERNARDES, R.S. Avaliação de aspectos políticoinstitucionais e econômico-financeiros do setor de saneamento no Brasil com vistas à definição de elementos para um modelo conceitual. Engenharia Sanitária e Ambiental. v.8, n.1, p.84-94, Jan./Mar. 2003.

TUROLLA, F.A. Politica de saneamento básico: Avanços recentes e opçôes futuras de politicas públicas. In: Texto para Discussão n. 922. Brasília. IPEA, 26 p. 2002.

Endereço para correspondência:

Alceu de Castro Galvão Junior Agência Reguladora de Serviços Públicos Delegados do Estado do Ceará - ARCE

Av. Santos Dumont, 1789 - $14^{\circ}$ Andar

60150-160 Fortaleza - CE - Brasil Email: alceugalvao@uol.com.br; mariomonteiro@arce.ce.gov.br

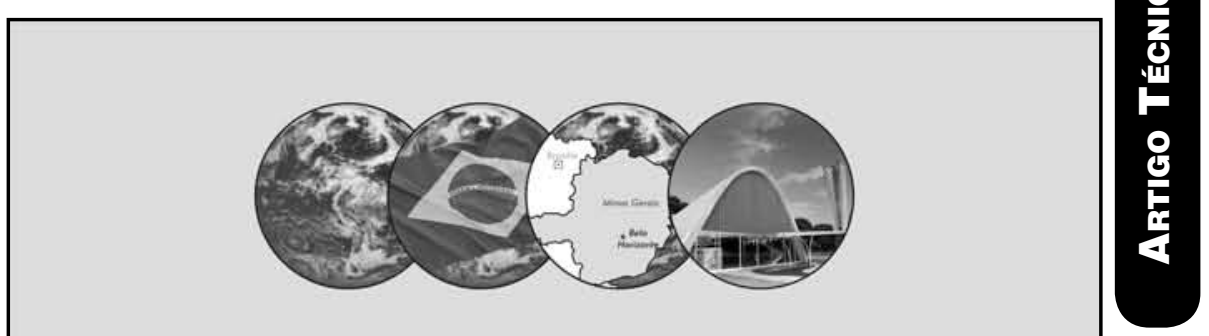

2 a 7 de setembro de 2007 EXPOMINAS

Belo Horizonte, MG - Brasil

Promoção / Realização: ABES ASSOCIAC̄AO BRASILEIRA DE
ENGENHARIA SANITARIA E AMBIENTAL AIMSS
Capitulo Nacional da AIDIS

\section{"Saneamento Ambiental: Compromisso ou Discurso?"}

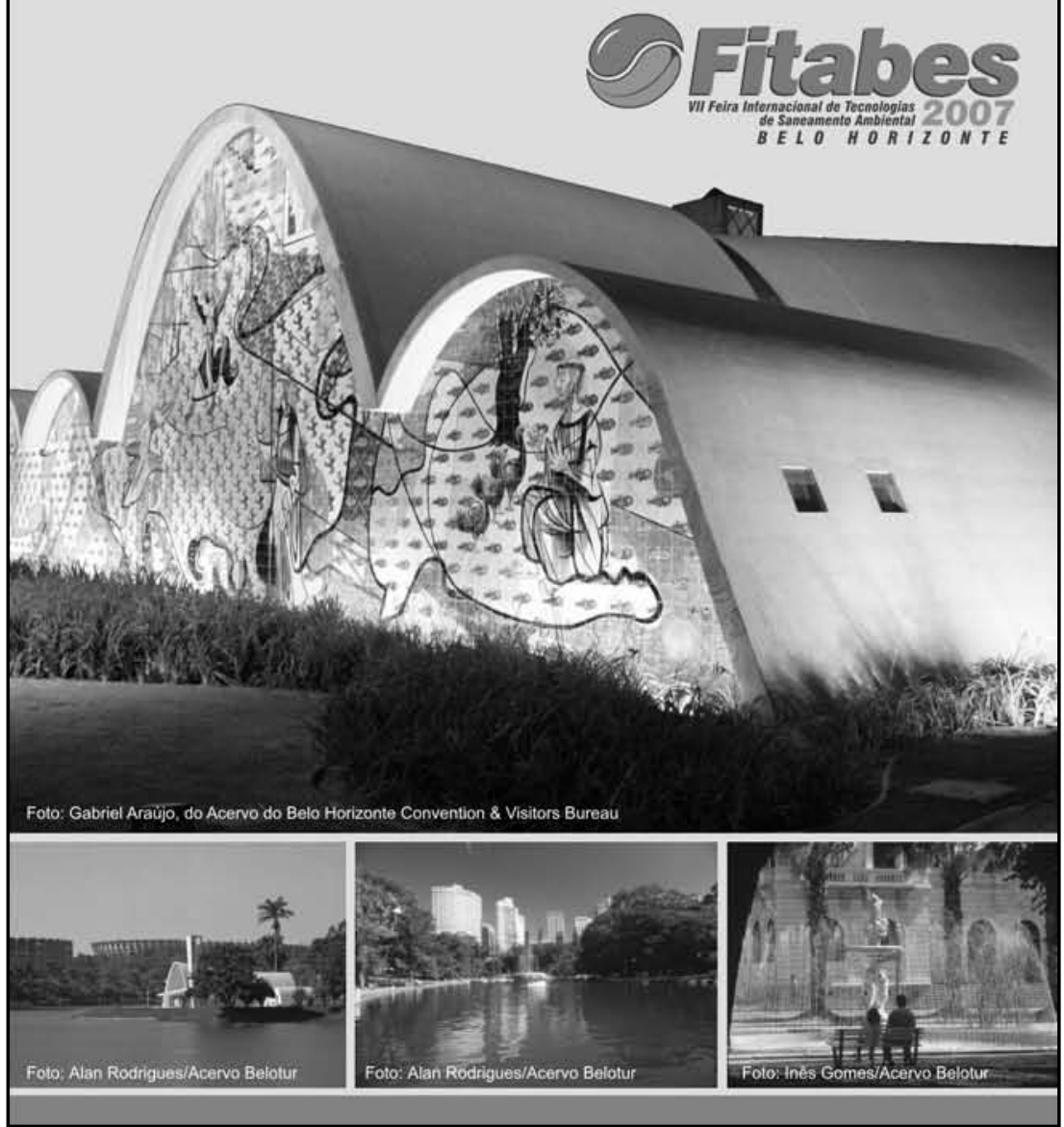

